\title{
The Role of THE COMMUNity Based REHABILITATION WORKER WITHIN THE PRIMARY Health Care Service of the Odi District
}

\begin{abstract}
Introduction: There has not been agreement within the Health Care Services regarding the role of Community Based Rehabilitation (CBR) NP TAUKOBONG workers. The training of $C B R$ workers continues although the process was not widely supported and the CBR worker's function has not been clarified yet CBR programmes are included in the training of students.

Aim: The aim is to identify and describe the role of the CBR workers within the Odi District Health Service (DHS) and determine whether they are fulfilling the rehabilitation and development functions envisaged by the WHO model of CBR programmes.

Methodology: Qualitative and quantitative research methods were used. These included a questionnaire; observations of the daily tasks of the CBR workers and interviews with members of the District Health Service (DHS) of the Odi district, clients and CBR workers. Open and axial coding were used in data analyses. Data from the different sources were triangulated to ensure trustworthiness.

Results: The skills performed by CBR workers have produced a change in the lifestyle of the disabled people and the initiated projects are benefiting the families of the disabled people within the CBR programme as well as their community. There seems to be a break down of communication between the District Health Manager (DHM) and the supervisor of the CBR workers. A lack of communication within the DHS affects the functions of the CBR workers.

Conclusion: It is concluded that, although the tasks of the CBR workers within the Odi DHS are not supported, they produce a positive impact on the quality of life of the disabled within the CBR programme. The CBR workers' contribution towards community development, although on a small scale, proves that they operate within the World Health Organization's (WHO) guidelines for CBR.
\end{abstract}

\section{KEYWORDS: COMMUNITY BASED REHABILITATION WORKERS, PRIMARY HEALTH CARE SERVICE, DISTRICT HEALTH SERVICE}

\section{INTRODUCTION}

The escalating number of people with disabilities, especially in the developing countries, has become a cause for concern amongst health professionals as well as health organisations.

In 1969 the International Society for Rehabilitation of the Disabled found that:

- the pace of training rehabilitation professionals was inadequate to meet the increase in health related demands;

- help could be given to the disabled in developing countries using methods consistent with available resources and the cultural as well as social patterns in these countries (Expert report, 1969).

Based on these findings the International Society for Rehabilitation of the Disabled recommended a change in technology, service delivery and a new type of manpower. This then saw the birth of Community Based Rehabilitation (CBR) which was first introduced in ten countries between 1979 and 1981 (WHO, 1981).

Helander (1994) defines CBR as a strategy for enhancing the quality of life of disabled people. This strategy was developed by the WHO following the Alma-Ata declaration and the recommendations by the International Society for Rehabilitation of the Disabled (WHO, 1981). India was amongst the first countries to introduce CBR programmes with the aim of alleviating the shortage of rehabilitation professionals. Through CBR programmes, the disabled people were assisted towards improving their functional abilities as well as addressing the welfare of their families and community.

Kenya initiated CBR programmes to provide rehabilitation services for the disabled in their communities where a definite need was identified (Kumar, 1996). Again in Agentina a CBR program was initiated in La Rioja province which currently serves $72 \%$ of the population (Momm, Konong, 1991). There are many more countries utilising the CBR programmes around the world especially in developing and under-developed countries (WHO, 1991). The above mentioned are but a few of those countries in which the primary goal is to improve rehabilita- tion services as well as health service delivery through CBR.(Helander, 1994)

In the Republic of South Africa (RSA), the shortage of rehabilitation professionals, with subsequent lack of rehabilitation services to the most needy (rural areas), prompted the inception of the CBR concept. In response, also, to the call "Health for all by the year 2000" the associations for occupational therapy, speech and hearing therapy and physiotherapy nominated a committee in 1987 which was mandated to look into the training of CBR workers as an initial step towards adopting the concept of CBR. The committee was therefore called the Committee on Community Rehabilitation Workers and consisted of representatives from the three associations mentioned above. In this process, the committee circulated a

CORRESPONDENCE: Ms N.P. Taukobong Department of Physiotherapy MEDUNSA 0204 Tel: (012) 5214485 
document containing a proposal for the training of CBR workers to all institutions training health professionals. This document requested constructive comments regarding this initiation of training $\mathrm{CBR}$ workers in RSA. There was total rejection of the concept by some academic institutions yet the training went on, with resultant establishment of training in Alexandra Clinic amongst the first established, in the early 90 's.

There are now a number of established centres around RSA.

In it's council meeting of the $31 \mathrm{st}$ March 1997, the South African Society for Physiotherapy (SASP) discussed the issue of CBR workers as rehabilitation professionals. No conclusion was reached at the end with regards to the position of the CBR workers within the rehabilitation services, yet a number of CBR workers are employed in the physiotherapy departments of certain hospitals. Some of the CBR workers have physiotherapists as designated supervisors. All these issues are disturbing as they affect people who are functioning within the health services, whilst having no attachment to a particular profession.

The National Minister of Health has expressed total rejection of this category which she refers to an "additional category" yet there are CBR workers practising around the country.

(DRC workshop report, 1996). The possibility exists that the Minister of Health is also concerned about who is going to pay this additional category of health worker whose role has yet to be fully defined.

All these problems or issues could be attributed to lack of knowledge about the contribution of CBR workers towards rehabilitation of the disabled, or their role as rehabilitation professionals. The researcher believes that if the role of the CBR worker can be described, those rejecting them could be made to understand their contribution in the health care system. These people may be made to eventually change their minds, whilst those who cannot make decisions will be assisted in reaching acceptable decisions.

\section{THE AIM}

The aim of the study was to identify and describe the role of the CBR workers within the PHC services of the Odi District. The secondary objective was to determine whether they are fulfilling the rehabilitation and development functions as described in WHO guidelines for CBR program.

\section{METHODOLOGY}

\section{Sumple}

Using the reformed RSA health system framework, the district health structure was used for selecting the sample. There are two existing CBR programmes, namely the Winterveldt and Oukasie, which fall under the Odi district in the North West Province. The sample included the District Health Manager (DHM), the Primary Health Care (PHC) nurse, the physiotherapist (designated rehabilitation co-ordinator and CBR worker's supervisor), a CBR worker from each program and the clients within the mentioned CBR programmes.

\section{DESIGN}

A qualitative design was used employing the triangulation technique. The technique included:

1. A self developed questionnaire, based on the guidelines for CBR described by WHO, completed by the CBR workers and containing open and close ended questions covering

- demography: to establish area of residence, training and employment.

referrals: to establish any referral system and by whom the clients are referred.

- assessment: to identify the aspects assessed, identification of the mobilityaids needs; as well as needs for adaptive devices and if they were assisted in identifying the clients problems.

treatment: to identify means of reaching the clients, where the clients are treated, whether the family members are involved and the procedures performed as well as supervision by rehabilitation professionals.

- projects: to identify projects initiated and whether they generate funds.

general: to acquire any useful knowledge regarding their role in the community.

2. Observations, a visit to the two programmes was conducted to obtain reliability in as far as handling of clients is concerned. The CBR workers activities observed included assessment, treatment, family involvement, treatment area and means of reaching the clients.

3. Interviews were conducted with all the members of the district rehabilitation team including the DHM to determine the truth-value as well as consistency of the information obtained from the questionnaires and observations. In order to identify whether the needs of the clients are met certain clients, selected by a sample of convenience, were interviewed from the two programmes.

\section{THE RESULTS}

The results obtained from the investigation will be summarised using the following framework (figure 1) which reflects the WHO guidelines for CBR as well as the activities within the Oukasie and Winterveldt CBR programmes:

\section{DISCUSSION}

The vision of the National Health Department in RSA, is to ensure improved quality of service at all levels hence the reformed District Health Systems (DHS) (Department of health, 1995; African National Congress, 1994). The districts are managed by the DHM with his/her management team. His responsibilities include ensuring that there is a rehabilitation plan and that all services rendered within the district are well co-ordinated (Helander, 1994). The results revealed that there was no rehabilitation plan. A lack of allied health professionals was cited as the main reason. On the other hand it was mentioned that there was a mechanism within the district for ensuring that the community level programmes such as CBR programmes, work in harmony with the other health delivery services in the district. Murphy et al (1992) fully supports such endevours by stating that WHO regards CBR as an integral part of PHC thus it is important for health managers to take cognisance of that fact.

Helander (1994) further stipulates that the CBR aspects, which ensure success of the programme, should also be an undertaking of the rehabilitation professional's responsibility as well. The study however showed that the supervisor is not involved at all and therefore has no responsibilities within the CBR programmes. This non involvement became apparent when the DHM stated that he does not feel the existance of $C B R$ workers and cannot comment on their contributions within the district services. The DHM reported this lack of feeling is, maybe, attributed to the fact that he receives no input from the physiotherapist/supervisor. This break in communication therefore explains the reason for the stated fears by the CBR workers. Momm et al, ( 1991); Murphy et al (1992) and other authors also agree that the success of the CBR programme is driven by the rehabilitation professional's involvement. It is believed that the service could spread even further through this involvement as mentioned 
The RSA health system is divided into three tiers

Tertiary Health Care
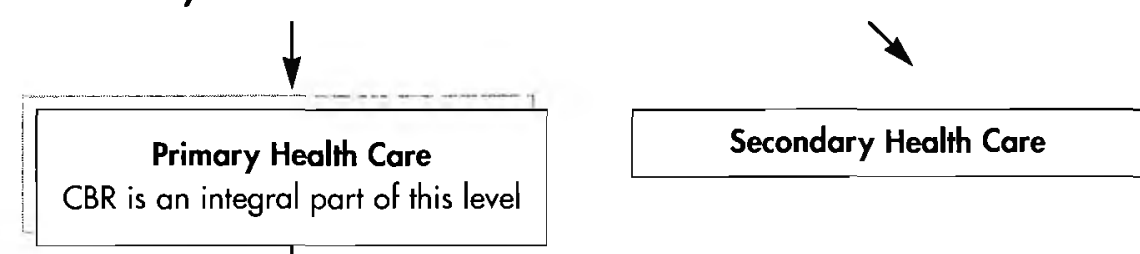

The DHM is the head of the DHS and is also responsible for community level services. He has no rehabilitation plan but a mechanism is in place for ensuring development within the district health service. There is a break in communication within the rehabilitation service.

The CBR workers are fearful of their future as rehabilitation staff as well as members of the health team. They voiced lack of recognition as professionals.

\begin{tabular}{|l|l|}
\hline Aspects of a successful CBR & $\begin{array}{l}\text { Expected CBR worker's skills } \\
\text { - rehabilitation plan } \\
\text { - active referral system }\end{array}$ \\
- monitoring system & $\begin{array}{l}\text { - identification of disability } \\
\text { - ability to assess limitations } \\
\text { - support structure }\end{array}$ \\
\hline
\end{tabular}

The physiotherapist is the designated supervisor and rehabilitation co-ordinator. She/he is not involved in the CBR services. She/he does not facilitate nor participate in the implementation of the CBR aspects. The PHC nurse has more contact with the $C B R$ workers and refers clients regularly to the $C B R$ program.
The CBR workers exhibit the ability to perform expected skills. They are supervised by the allied health professionals outside their district services. Their skills have influenced the life of disabled members of the community involved in the CBR program

Clients and the CBR workers have established projects for which they are jointly responsible. The projects do produce products which are needed and used by the community, although on a small scale.

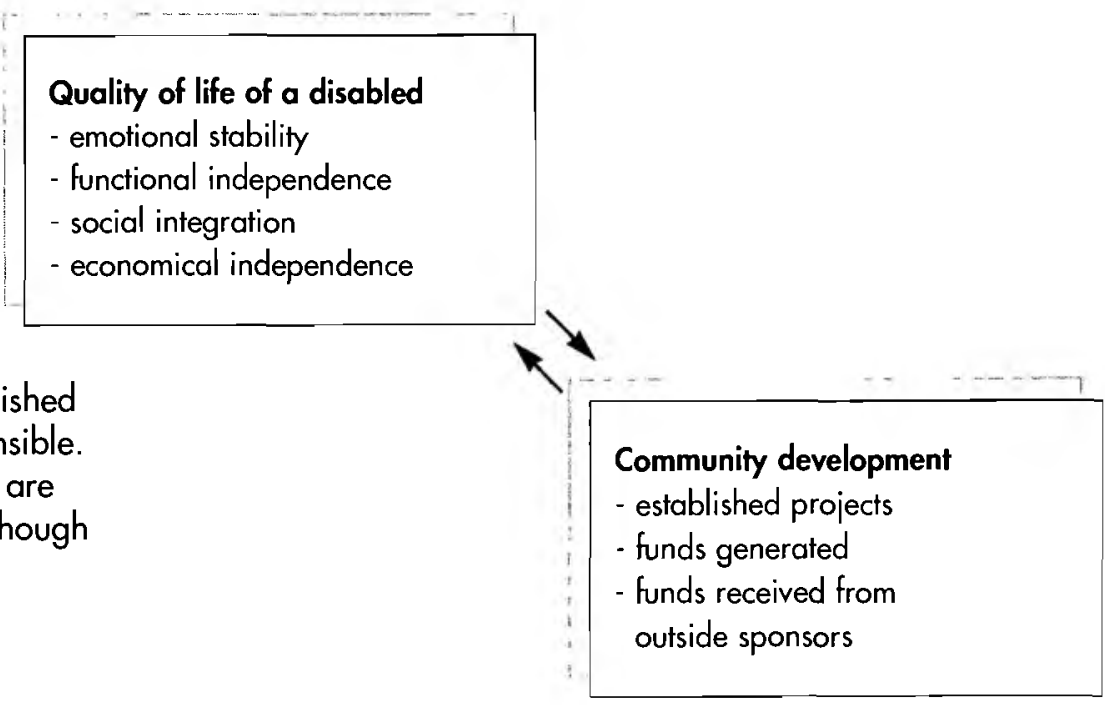


by the PHC nurse when she said "There are many disabled people who need this service and to reach all of them the $C B R$ worker needs the assistance of a professional person". The results also revealed that the CBR workers are supervised by allied health professionals outside the district health system which may be another contributing factor towards their fears

Both CBR workers commenced this service as volunteers within their communities before they were trained as CBR workers, which is one of the important principles of a CBR programme (Murphy et al, 1992). In the spirit of "Masakhane" in the RSA, the national government is trying to impart a sense of responsibility amongst community members (African National Congress, 1994). It is evident that the CBR workers at Winterveldt and Oukasie, have exhibited this social responsibility by striving to help their own community members to improve their way of life. These endevours should be seen as a basis for government as well as community support which were found to be very minimal within both programmes. The CBR worker's skills as stipulated by the WHO model (Murphy et al, 1992; Helander, 1994 ) were all exhibited by the two CBR workers within the CBR programmes. This implies that the CBR workers, using these skills, are capable of influencing the functional abilities of the disabled people.

According to the rehabilitation definition by the WHO in 1981 the existence of social integration reveals that the aim of rehabilitation has been achieved (Expert report, 1969; Helander, 1994). This has been the case with the studied CBR programmes as depicted from some of the client's responses such as: "I now feel like a normal person again because I am not afraid to associate with members of my community". This impact has also been shown in a study conducted at Tintswalo about the CBR worker's influence on the disabled (Dolan et al, 1995). It is evident that some of the existing CBR programmes within RSA are comparable to programmes in other countries that are successful (Kijanski, 1995; Tiroler, 1995 . Kumar, 1996).

Community development has occurred as evidenced by established projects although on a small scale because of minimal or lack of funding from the outside sponsors. The disabled people are generating funds from the projects which is some sign of development. (Murphy et al, 1992) The projects generate a source of income for supporting the disabled and their families. The products produced, such as vegetables and candles, are relevant to the needs of the community as both Winterveldt and Oukasie are very poor and under - developed. This means that the projects are in line with other projects in developing countries, which meet the needs of the poor communities and contributes towards community development ( Murphy et al, 1992; Kumar, 1996).

\section{CONCLUSION}

It is concluded that the CBR worker's in the Odi district are producing a positive impact on the emotional, social, functional and economical needs of the disabled community members involved in the CBR programmes although their tasks are difficult. Community development exists through the established projects, although on a small scale, hence their role is consistent with the envisaged functions of the WHO model for CBR.

\section{LIMITATIONS}

The study was conducted amongst the CBR workers at Winterveldt and Oukasie only and whilst there are a number of CBR workers around the country the results cannot be generalized.

\section{RECOMMENDATIONS}

It would be interesting to learn about the impact produced by other CBR programmes within the country with the view of further supporting the role of the CBR worker. The researcher believes that such a knowledge would motivate for recognition of the CBR workers. A wide scale study including the other CBR programs is thus recommended.

\section{ACKNOWLEDGEMENTS}

Many thanks to Dr. C.A. Eksteen, Ms N. Mtongwana, the two CBR workers as well as all other participants without whom this study would not have been a success.

\section{REFERENCES}

Murphy SP, Gopal L (1992); Workbook on community based rehabilitation services. National Printing Press. Bangalore, INDIA.

Report of a meeting of experts (1969). International Society for Rehabilitation of the Disabled. IRELAND

Helander (1994); Prejudice and Dignity. An introduction to community based rehabilitation. UNDP. GENEVA, Switzerland.

WHO (1981); Disability Prevention and Rehabilitation. Report of the WHO Expert
Committee on Disability Prevention and Rehabilitation. WHO No.668. GENEVA.

WHO (1987); The community health worker working guide. GENEVA.

Kisanji J (1995); CBR news. Vol. 19, Jan - April: $4-6$

Tiroler G (1995); CBR news. Vol. 21, Sept - Dec: $4-5$.

Kumar P (1996); CBR news. Vol. 23, May - Aug 1996: 3.

CBR in Swaziland (1993); Video on the CBR worker's experiences. SWAZILAND.

Jackson H (1993); Challenging disability: A guide for frontline workers in Africa. Speciss Print 'n Mail. ZIMBABWE.

Hoggenhoudegen K, Vaughan P, Muhondwa E, (1997); Community health workers: The Tanzanian experience. Oxford University Press, NAIROBI.

Institute of Urban PHC. Information brochure Department of Health (1995); Towards a national health system.

Office of the Deputy President T.M. Mbeki (1997); White Paper on Integrated National Disability Strategy for SA.

African National Congress (1994); Reconstruction and Development Programme: A policy framework. Umanyano. JOHANNESBURG.

Physiotherapy Forum (1997); Vol. 1I, No.5, July: News from the world of Physio: More news from the professional board. p.15.

Department of Health (1995). A policy document for the development of district health systems for SA (1995).

Report back on the CBR workshop held with the Director: chronic disease, disability and geriatrics (1995).

Report on the DRC workshop held at Medunsa (1996).

Programmes: Experiences and reflections on a new concept of service provision for disabled people. WHO, GENEVA.

WHO (1994): A guide for health sector policy formulation and programme planning for CBR. WHO/RH5.94, GENEVA.

WHO: (1992) The education of mid level workers: Recommendations from country experiences. Rehabilitation, GENEVA.

Dolan ME., Concha ME., Nyathi E. (1995); Community rehabilitation workers: Do they offer hope to the disabled people in S.A's rural areas? International Journal of rehabilitation Research 18(3): 187-200.

Helander E., Mendis P., Nelson G. (1983); Training disabled people in the community. A manual on CBR for developing countries. RHB/83.1: WHO, GENEVA

Committee on Community Rehabilitation workers: (1987): Memorandum on community rehabilitation workers 